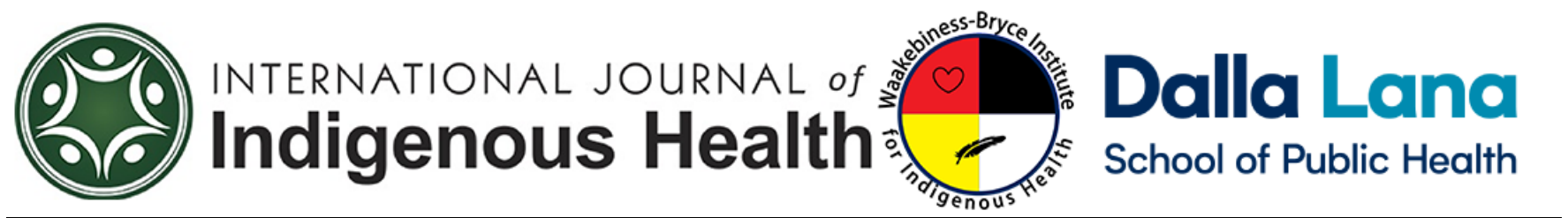

Volume 14

Issue 2. Growing Roots of Indigenous Wellbeing

Article 12

Full Issue DOI: 10.32799/ijih.v14i2.32958

October 2019

\title{
Indigenous Youth Development through Sport and Physical Activity: Sharing Voices, Stories, and Experiences
}

Mark W. Bruner, PhD, Professor and Canada Research Chair in Youth Development through Sport and Physical Activity

School of Physical and Health Education, Nipissing University markb@nipissingu.ca

\section{Robert Lovelace}

Department of Global Development Studies, Queen's University

lovelace@queensu.ca

Sean Hillier, PhD, Assistant Professor

School of Health Policy \& Management, York University

shillier@yorku.ca

Colin P.T. Baillie, MSc

School of Kinesiology and Health Studies, Queen's University

colin.baillie@queensu.ca

\section{Brenda G. Bruner, PhD, Professor}

School of Physical and Health Education, Nipissing University

brendab@nipissingu.ca

Kathy Hare

Motivate Canada

keh@sportlaw.ca

\section{Christine Head, MSW}

Motivate Canada

headchristine@hotmail.com 


\section{Aaron Paibomsai, BPHE}

School of Physical and Health Education, Nipissing University

atpaibomsai936@community.nipissingu.ca

\section{Kieran Peltier, BSc in Sports Strength and Conditioning}

School of Physical and Health Education, Nipissing University

kpeltier783@community.nipissingu.ca

\section{Lucie Lévesque, PhD, Professor}

School of Kinesiology and Health Studies, Queen's University

levesqul@queensu.ca

Follow the International Journal of Indigenous Health at:

https://jps.library.utoronto.ca/index.php/ijih/index

\section{Recommended Citation}

Bruner, M., Lovelace, R., Hillier, S., Baillie, C., Bruner, B., Hare, K., ... Lévesque, L. (2019).

Indigenous Youth Development through Sport and Physical Activity: Sharing Voices, Stories, and Experiences. International Journal of Indigenous Health, 14(2), 222 - 251. DOI

10.32799/ijih.v14i2.31945 


\title{
Indigenous Youth Development through Sport and Physical Activity: Sharing Voices, Stories, and Experiences
}

\begin{abstract}
Recent research has highlighted the cognitive, physical, emotional, and spiritual benefits of sport and physical activity participation for Indigenous youth (McHugh, Coppola, \& Sinclair, 2013; Hanna, 2009; Lavallée, 2007). Despite the importance of Indigenous peoples participating in sport and physical activity (e.g., Forsyth \& Giles, 2013), the meaning of youth development in this context is not well understood. The purpose of this research was to understand Indigenous youth development within the context of sport and physical activity through the voices, stories and experiences of Indigenous youth. Participants were 99 Indigenous youth (52 males and 47 females) between the ages of 15 and 25 years who took part in one of 13 sharing circles. Each of the sharing circles was facilitated by a trained Indigenous youth with guidance from an Elder/Traditional person. A Two-Eyed Seeing approach (Bartlett, Marshall, \& Marshall, 2012) was used to analyze the sharing circle discussions. This analytical process involved an initial inductive thematic analysis of the transcribed verbatim data followed by an Indigenous symbolic visual analysis of emerging themes using the Medicine Circle. Results revealed that involvement in sport and physical activity impacted Indigenous youth physically, cognitively, and emotionally. The spiritual impact was not as evident. Findings from the research will inform the development of a measure of Indigenous youth development within sport and physical activity settings.
\end{abstract}

\section{Keywords}

Indigenous, Qualitative, Adolescents, Medicine Wheel

\section{Creative Commons License}

\section{(a) $(\Theta \Theta$}

This work is licensed under a Creative Commons Attribution-Noncommercial-No Derivative

Works 4.0 License. 


\section{Acknowledgements}

The authors wish to thank the Active Circle Governing Council and Donna Ivimey for their contributions to the manuscript. This research was supported by a grant from the Canadian Institutes for Health Research (CIHR), Institute of Aboriginal Peoples' Health (IAPH), and Health Canada - First Nations and Inuit Health Branch (FNIHB) (CIHR Grant \#AHI 120532)

\section{Introduction}

Sport and physical activity involvement has been associated with a number of physical and psychological benefits for youth including opportunities to interact with peers, to learn fundamental motor skills, and to enhance psychosocial development (Allen, 2003; Côté \& Fraser-Thomas, 2011). Outcomes related to these opportunities are often referred to as positive youth development (PYD). PYD is a strength-based perspective of adolescent development that recognizes that all young people hold the potential for positive, successful, and healthy development (Lerner et al., 2005). There is mounting empirical evidence to support the salient role of sport and physical activity in fostering PYD in youth (Eccles, Barber, Stone, \& Hunt, 2003; Fredericks \& Eccles, 2006; 2008). To date, the bulk of this research has been conducted with Euro-American populations while minimal work has included Indigenous ${ }^{4}$ youth (Bruner et al., 2016).

It is essential to consider an Indigenous perspective to youth development through sport and physical activity because optimal youth development from an Indigenous perspective typically goes beyond healthy emotional and mental development to include other aspects of the person (e.g., body and spirit; McHugh, Deal, Blye, Dimler, Halpenny, Sivak, \& Holt, 2018). For example, research has highlighted the cognitive, physical, emotional, and spiritual benefits of sport and physical activity participation for Indigenous youth (McHugh, Coppola, Sinclair, 2013; Hanna, 2009; Lavallée, 2007). Indigenous sport and physical activity have been used to teach personal and social values such as honesty, respect, courage, personal excellence, and gratitude toward parents, Elders and communities as youth move toward adulthood (Canadian Heritage, 2005; Lockhard, 2000). This multidimensional conceptualization of youth development can take the form of a Medicine Wheel that includes the physical, emotional, mental, and spiritual dimensions of self (Lavallée, 2008; National Aboriginal Health Organization, 2005). Optimal development is characterized by balance between these four dimensions of self, rather than by a binary view (e.g., positive versus negative). The concept of youth

\footnotetext{
${ }^{4}$ This paper will use the non-colonial term Indigenous when referring to and discussing First Nations (status and non-status), Métis, and Inuit Peoples as a group. Periodically, throughout this paper the terms Native, Indian and Aboriginal will be used, but only when there is a direct reference to these terms through policy or other direct quote (Hillier, 2019).
} 
development from an Indigenous perspective thus considers human development from a wholistic and relative standpoint (FNIGC, 2012; Royal Commission on Aboriginal Peoples, 1996). Finally, an Indigenous perspective to youth development places a stronger emphasis on the contribution of community to the growth and flourishing of youth than is typically articulated in mainstream conceptualizations of PYD (Lavallée, 2009; McHugh, Coppola, Holt \& Andersen, 2015).

Etuaptmumk, or a Two-Eyed Seeing approach (Bartlett, Marshall, \& Marshall, 2007; 2012; Bartlett, Marshall, Marshall, \& Iwama, 2015), considers both Indigenous and Western epistemological conceptualizations of the world and offers an ideal framing to further our understanding of PYD among Indigenous youth. Albert Marshall, the Mi'kmaw Elder who introduced the concept describes Two-Eyed seeing as " $[\mathrm{t}]$ o see from one eye the strengths of Indigenous ways of knowing, and to see from the other eye with the strengths of Western ways of knowing, and to use both of these eyes together" (Bartlett, Marshall, \& Marshall, 2012, p. 335). Two-Eyed Seeing relates to seeing the world through Indigenous worldviews alongside Western or European perspectives (Bartlett, Marshall, \& Marshall, 2012). This approach draws on the strengths of both perspectives to create a shared understanding of a topic (Hovey, Delormier, McComber, Lévesque, Martin, 2017) and given its strengths is increasingly being used by scholars to bridge Indigenous knowledges with the use of Western method and theory (Peltier, 2018). For example, Lavallée and Lévesque (2013) used a Two-Eyed Seeing approach to discuss the promotion of physical activity, sport and recreation by integrating the Medicine Wheel teachings of the Anishnaabek and the Social Ecological Model (Bronfenbrenner, 1977; 1979; Stokols, 1992).

Despite the importance of participation by Indigenous peoples in sport and physical activity (e.g., Forsyth \& Giles, 2013), the meaning of youth development from an Indigenous perspective is not well understood. There is a need to explore the experiences of Indigenous youth in sport and physical activity and how these settings contribute to youth development. Thus, the purpose of this research was to understand Indigenous youth development through sport and physical activity through the voices, stories, and experiences of Indigenous youth using a Two-Eyed Seeing approach.

\section{Method}

\section{Ethics and Recruitment}

Prior to conducting the research, ethical approval was obtained from the Institutional Ethics Review Boards of the three participating universities, the Office of Indigenous Initiatives of one of the Institutions, as well as from community governing bodies in instances where sharing circles took place on-reserve. A scientific research license was also obtained from the Nunavut Research Institute to conduct a sharing circle in Iqaluit. 
To recruit First Nations, Inuit and Métis youth to participate in the research, student researchers and research coordinators made contact with local youth, Indigenous organizations, and community leaders from their networks and programs. In some cases, where there were no established connections, recruitment posters were distributed to local youth and Indigenous organizations. In other cases, word of mouth and personal invitations were used in the recruitment process. Nine sharing circles were initially planned. However, following a discussion with the research project's Governing Council - comprised of 11 Indigenous community members and 11 research team members ( 6 of whom identify as Indigenous) - four additional sharing circles were conducted to address the need for stronger representation of reserve/rural and Métis youth. These additional sharing circles were held in reserve/rural $(n=3)$ and urban $(\mathrm{n}=1)$ settings.

\section{Participants}

Participants were 99 self-identified Indigenous youth (47 females and 52 males) between the ages of 15 and 25 years who took part in one of 13 sharing circles. A broad sampling of Indigenous youth was recruited from 10 communities ( 7 urban, 3 reserve/rural) across Canada from British Columbia to Nunavut to Newfoundland and Labrador. Youth provided verbal or written consent, including being able to give consent in accordance with their local cultural protocols (e.g., through the use of tobacco).

\section{Sharing Circles}

Sharing circles were conducted with youth to gather their experiences and stories in a comfortable group setting (McHugh et al., 2013). Sharing circles have previously been used in sport and physical activity research with Indigenous peoples (Baillie et al., 2016; Blodgett et al., 2010; McHugh et al., 2013; Schinke et al., 2010). While similar to focus groups, sharing circles also hold sacred meaning among many Indigenous cultures (Lavallée, 2009). Sharing circles promote a culturally respectful research environment by supporting the sharing of experiences and stories in a group setting.

One of the sharing circle facilitators ( 2 male, 1 female), all of whom self-identified as Indigenous youth members of the research team, provided instructions to the participants regarding the conduct of the sharing circle. Each sharing circle facilitator followed a semi-structured interview guide (see Table 1). Each participant in the sharing circle waited their turn to speak; often an Eagle feather or cultural symbol was passed among participants as a reminder for the group to respect and listen to the speaker (person holding the symbol). During the sharing circle, the Elder or cultural person and the facilitator actively contributed their knowledge to the discussion when it was their turn. Once each participant had spoken, participants were given another opportunity to share their thoughts about each question. At the 
conclusion of the sharing circle, the Elder or cultural person offered a closing. Sharing circles lasted between 26-79 minutes.

\section{Data Analysis}

Sharing circle data were transcribed verbatim, yielding 188 pages of transcripts, which were uploaded into NVivo 10. A selection of the transcripts were compared to audio files to ensure accuracy of the transcripts. The data analysis was guided by the Indigenous knowledges and worldviews held by two Indigenous team members who conducted the coding/analysis. Team members all identified with a wholistic perspective that recognizes the relationship with Mother Earth. Given the breadth and depth of participant backgrounds and the significant amount of data to be coded, it was determined the best way forward was to rely on the background and knowledges held by these two team members who brought their diverse cultural background and teachings to the data analysis. The research team explicitly sought to interpret the data with respect for its epistemological origins and with the intended outcome in mind i.e., to understand Indigenous youth development through sport and physical activity through the voices, stories and experiences of Indigenous youth using a Two-Eyed Seeing approach. At the end of this process, the research team re-engaged with the governing circle to present the results of the analysis process for their feedback and comment. Using an inductive, "bottom-up" approach, a single Indigenous member of the research team thematically coded all of the transcripts, assigning descriptor 'nodes' to the verbatim text (Braun \& Clarke, 2006). Upon completion of this stage, a second Indigenous member of the research team reviewed the coding adding additional nodes where relevant. The two Indigenous researchers then met to discuss the overall coding, eliminating duplicates and noting the rationale for specific nodes before arriving at a final coding. A senior, non-Indigenous member of the research team then reviewed a portion of each of the coded transcripts to ensure consistency and accuracy of the analysis process. Next, all of the Indigenous and non-Indigenous research team members, including the coders, came together to review the coded nodes. These nodes were then placed into categories (i.e., subthemes) based on their context and relevance to other nodes. Finally, "higher order themes" were created based on the data (Braun \& Clarke, 2006).

Following the development of the higher order themes, team members discussed the use of an Indigenous approach to better represent the experiences shared by Indigenous youth across Canada. Team member R.L. told the story of the "Bone Woman", an old story he had heard as a child and later found in Women Who Run with the Wolves (Estés, 1992) that helped everyone to understand how to apply an interpretation of a narrative expression. The story begins with an old woman living in a dry place; she collects bones. One day having collected all of the bones that she can, she begins to examine them. She recognizes the skeleton of a wolf. She then begins to drum and sing and the wolf comes to life again. The wolf then runs to the eastern horizon where it reveals itself as a young woman. This is a strong healing story and writing it does not come close to its oral telling, but through the storytelling 
experience, the team could see how the narrative emerging from the data took on first, emotional qualities, and then moved to a cognitive quest to identify, then to a spiritual ceremony through the drum and song, and finally to a re-creation of being and a place of renewal. At this point, the research team understood that the processes of connections between emerging themes had to be oriented visually. The challenge was to "visualize" process and relationships and to represent these perceptions graphically in symbolic form. This moved the methodology into Indigenous Symbolic Analysis (McNiff, 1998); symbolism regulates the traffic of spoken words into multiple yet predictable units of meaning. This process involved the elaboration of an analytical structure through the use of a graphic symbol - the Medicine Wheel - and a narrative analysis that extended the previously coded nodes and higher order themes into wholistic process (i.e., verb) based configurations having dynamic positions on the graphic (see Figure 1). This methodological approach using traditional oral teachings was led by Indigenous team members.

Figure 1. Medicine Wheel

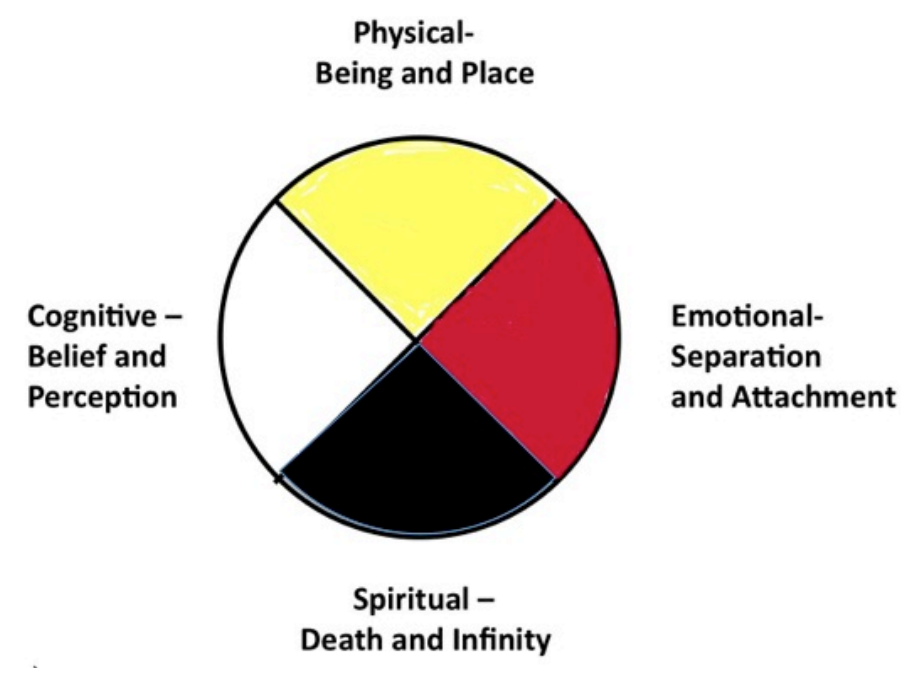

The Indigenous members of the team explained that this interpretation of the Medicine Wheel, among others, is divided into quadrants and each quadrant is informed by attributes that form balanced binaries. The 'physical' is informed by 'being' and 'place'. 'Being' can be defined by qualities such as gender, genetics, innate personality, human characteristics, etc. while 'place' can be defined by the spatial dimensions that a person occupies. The quadrant labeled 'emotion' is informed by an active binary 'separation' and 'attachment'. Human emotions facilitate this binary in order for relationships to be dynamic. In this way, communities evolve. Human experience includes the mystical or what we often refer to as spiritual or what some might consider a strong human inclination to know the unknowable. This binary allows us to understand both the meaning of 'death' and 'infinity'. Cognitions, or knowing, are arrived at through a binary of 'belief' and 'perception'. 'Beliefs' are the frameworks in 
which we test and qualify perceptions. 'Perceptions' are the grain and grist that feed and shape beliefs. At this point, one of the Indigenous team members (R.L) shared his preference for the use of the term 'circle' as opposed to 'wheel'. This preference is based on what he learned growing up and over the last 50 years through experiential learning with elders and others. As he described:

It [a circle] is a shape that is moving. In fact, it is movement. It is flexible and not always perfectly round, and in reality, subject to symbiotic relationships with the in, the in-between and the around. Like most words in indigenous languages it is energetic, animate. The way to conceptualize "circle" is as a verb and "wheel" does not measure up to that. Western Languages require paragraphs to express what many indigenous languages do efficiently with grammar. The Algonquin root word for "circle" is a conjunctive verb tibìdà. It is used to compound other words to indicate the shape of motion. There are still other words that emphasize both place and specific action but include the idea of circular shape or intention. Indigenous vocabulary and grammar emerge as functional representations of experienced ecological relationships and interchanges that are observed and cognitively considered within a previously established epistemology. In Algonquin the word for "wheel" is titibayàgan a grammatical variation of the root word tibìdà that makes it a noun. Its meaning is "a thing that rolls" and is specific to the mechanical definition in English. In all likelihood, a wheel in Algonquin, while being seen as circular is a specific kind of object and not to be confused as the unified meaning. Applying indigenous analysis to psychology or sociological methods is done no differently when looking toward identifying the contextual meaning of word translation (Robert Lovelace, oral transmission, December 12, 2013).

It is based on this preference that the term "Medicine Circle" is used from this point on. After choosing the Medicine Circle framework, the next step was to understand how to find "place" on the Medicine Circle for the data. To accommodate narrative interpretation in a wholistic manner, the Medicine Circle used in this study was conceptualized with additional dimensions. As depicted in Figure 2, we added to the diagram an axis representing the relationships between Physical and Spiritual, and Cognitive and Emotional dimensions. Nodes placed on this axis demonstrate the relative influence of these binaries' attributes. An example is an intention expressed through the original node narrative, which identifies hunting as a metaphysical as well as a physical activity. This node was placed on the Physical/Spiritual axis. Additionally, to symbolise the flow of energy around the circle connecting two, three, or four attributes, we added coloured arcs. As the intentions of narrative nodes were identified, they were also placed on the relative continuum of one of these arcs. The "white" ground is meaningful 
as it denotes negotiated areas where mutual relativity can be expressed between two adjacent attributes. In this way, every node intention finds grounded meaning somewhere within the circle and represents dynamic relationships with other nodes and wholistic attributes.

\section{Figure 2. Indigenous Youth Development Medicine Circle}

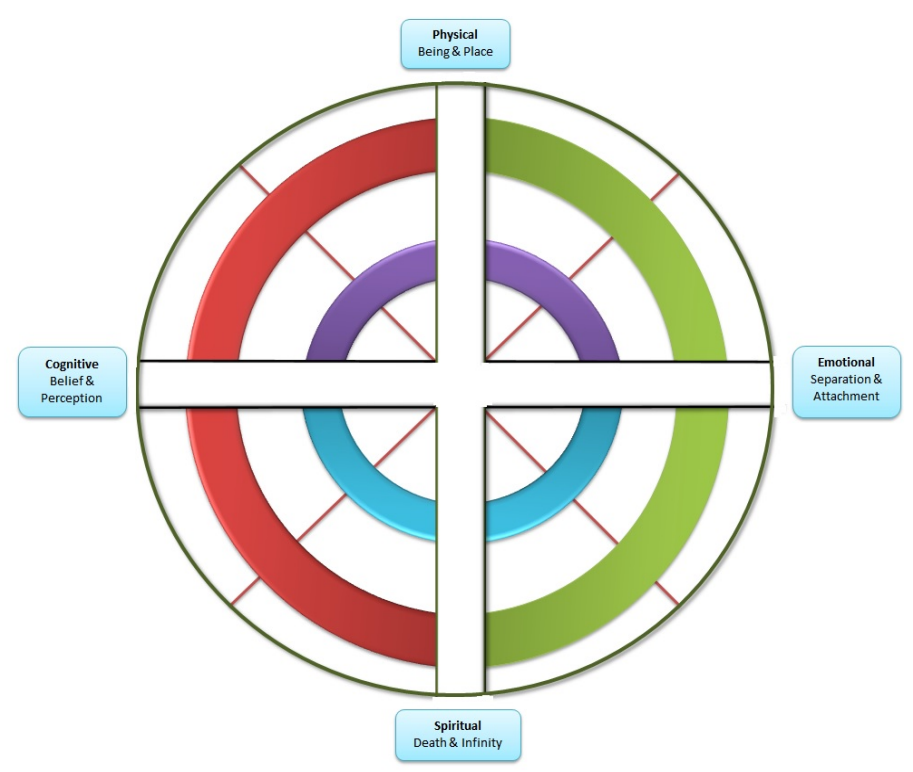

Each of the previously determined nodes, under a specific higher order designation was reviewed. The same, but separate Medicine Circle layouts were used for each higher order theme. Using NVivo10 to recognize patterns, we reviewed narrative intentions expressed by sharing circle participants. The team discussed placement of each node on the Wheel. Determining intentions of nodes was achieved by the research team, using consensus building ${ }^{5}$ on the meaning and value of the narrative expressions. The objective was to reach "one mind" in "seeing" how wholistic relevance could be found for each data node by working together as a research team. It was essential to understand the context in which nodes originated. In the process of placing nodes, some were easily identified while others needed more negotiation. The process, as a collective exercise, was useful because it led to a fuller understanding of the applicability of the methodology. Figure 3 illustrates how assembling the Indigenous youth narratives in higher order themes and then arranging these visually within a culturallyspecific Medicine Circle, yielded a dynamic symbolic ecology.

\footnotetext{
${ }^{5}$ Consensus building is an indigenous method of problem solving. It does not rely on compromise but rather on exploring possibilities without preconceived determinations (Lovelace, 2009).
} 
Figure 3. Higher Order Themes of Indigenous Youth Development Medicine Circle.

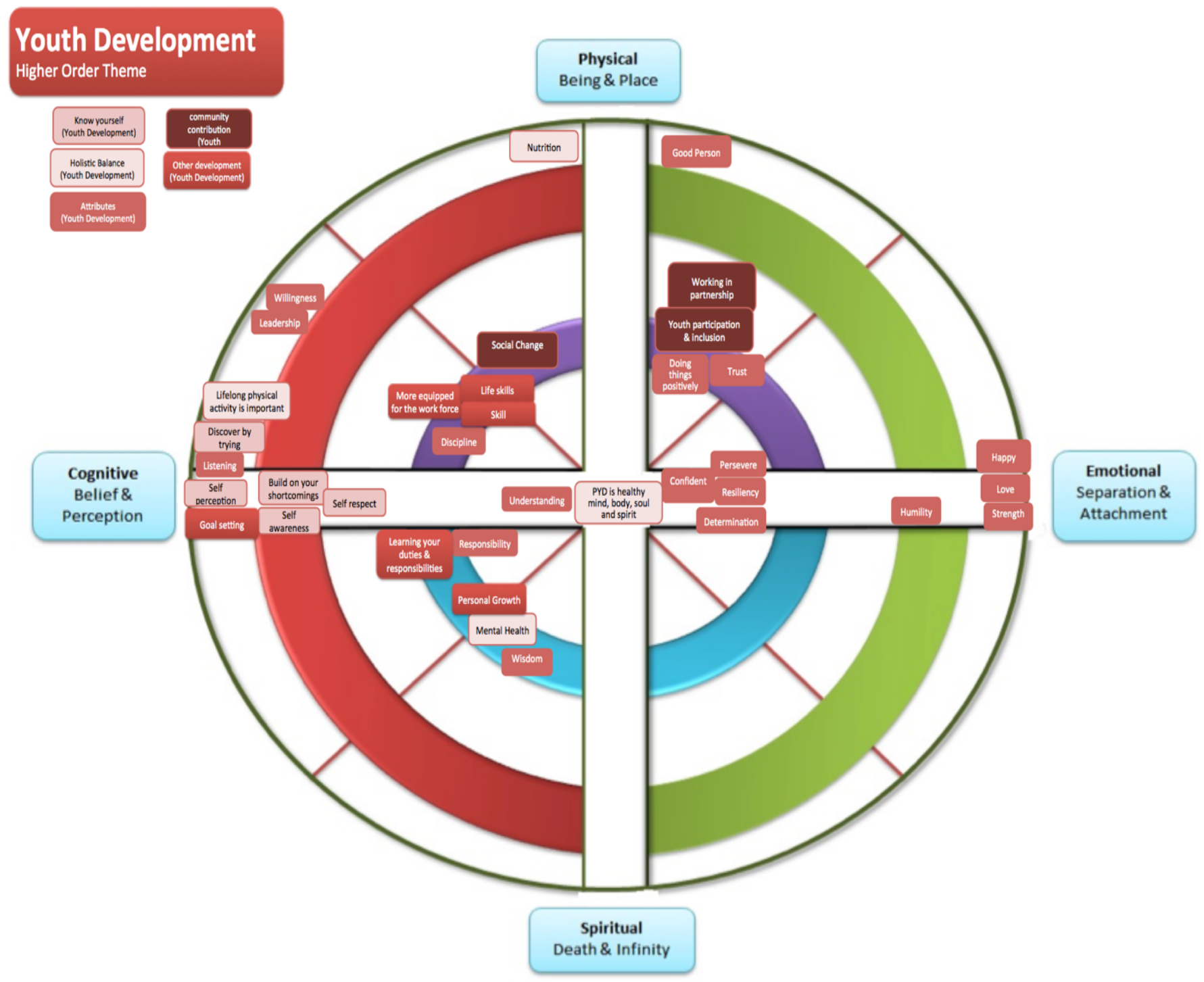

\section{Results}

The implementation of a Two-Eyed Seeing approach involving inductive coding and an Indigenous Symbolic Analysis revealed ten higher order themed Medicine Circles: youth development, culture, connection, supports, self, physical activity outcomes, education, negative life experiences, barriers to physical activity, and physical activity and recreation. Several of the higher order themes 
were comprised of subthemes/nodes (see Figure 4 for an overview of the themes and subthemes) ${ }^{6}$. Each theme and its associated subtheme(s) presented below are supported by the voices of First Nations, Inuit, and Métis youth and Elders. Participant coding incorporated information on participant demographic information (Indigenous youth or Elder, Indigenous identity, and gender) when reported.

Figure 4 Overview of theme and sub-theme coded nodes on the Indigenous Youth Development Medicine Circle.

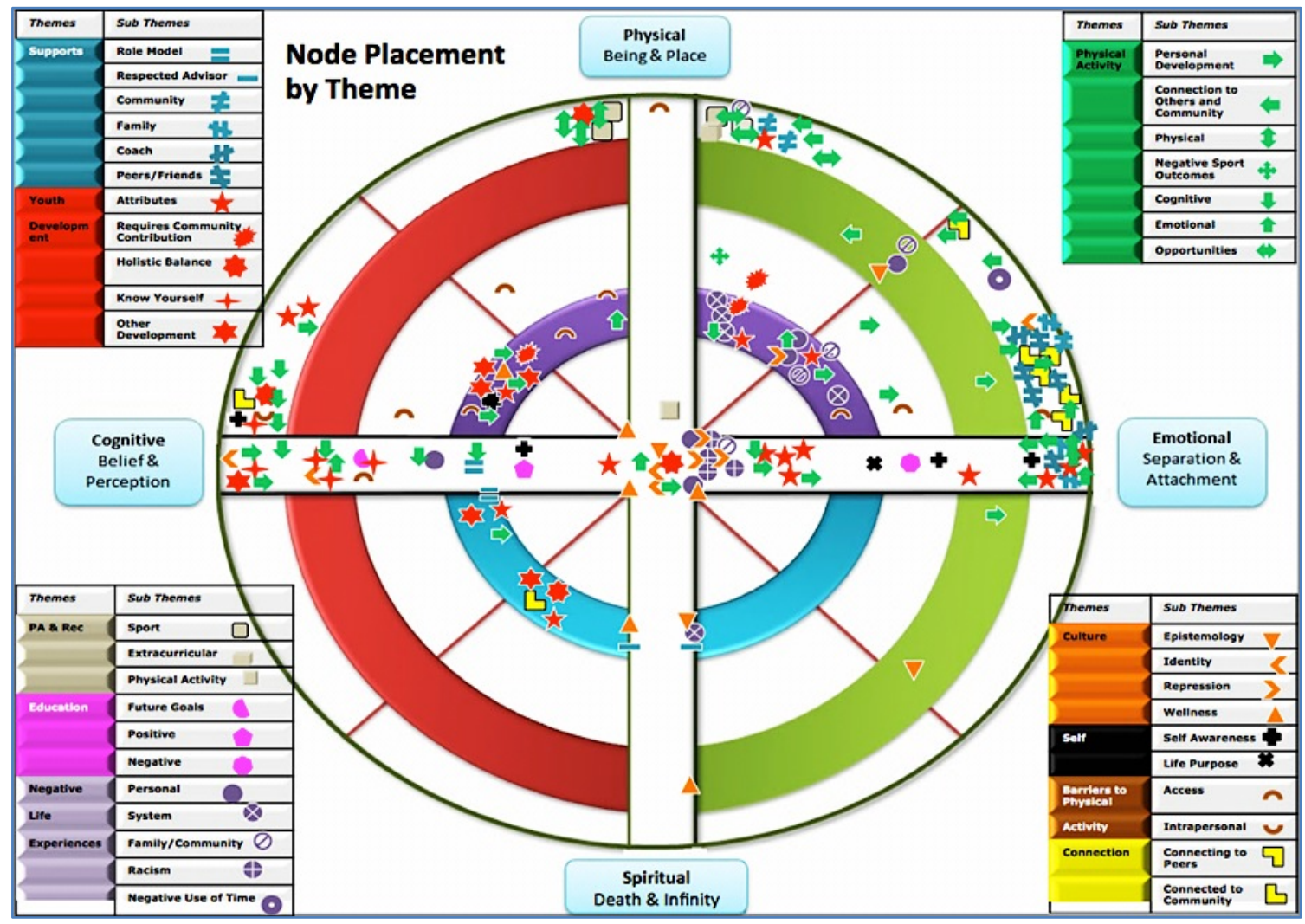

\section{Youth Development}

Participants described youth development through engagement in sport and physical activity highlighting wholistic balance, developing positive attributes, learning about oneself, and developing other life skills. An example quote of wholistic balance was provided by a First Nations female youth:

\footnotetext{
${ }^{6}$ Please see Appendix A for individual examples of the 10 themes of coded nodes on the Indigenous Youth Development Medicine Circle.
} 
Learning is a balance and everything has to be part of the project... you can't be too much into something and too much into something else. What I've learned now, being an adult is like what you're saying is spiritual, mental, emotional, being a part of ceremonies, being in sports, being a part of a family, it all kind of, runs together (First Nations, Female Youth).

The following quote from a First Nations male youth exemplifies developing positive attributes:

When I think of youth development I think of...being active, staying healthy, you know, it can help you a lot in the future...And it also makes you feel more confident about yourself, and about trying different things that you usually don't do (First Nations, Male Youth).

A learning about oneself example quote was provided by an Inuit female youth participant:

Um, when I think of youth development...I think that, youth discovering themselves as being capable for and having...Having the examples to develop themselves to be capable... because it's really all through their own self-discovery. They can't be kind of told...it has to be, like, they start to discover that they are more capable by trying and, like through sports and if you don't try you never really know (Inuit, Female Youth).

Finally, an example quote of developing other life skills was provided by a Métis female youth reflecting on what she felt was important for youth development:

I think that youth participation and inclusion is, ah, also really important...And, like, developing life skills so, like you said, we all have different circumstances but working with youth on their circumstances to make sure that they have the tools to succeed in life as well. (Métis, Female Youth).

\section{Culture}

Participants discussed the positive cultural impact of sport and physical activity engagement on identity development, epistemology, and learning about health and wellness. An example quote of identity was provided by a participant:

I have learned a sense of pride in myself, and who I am, and I have learned to be strong and to feel good about myself and comfortable with myself and that no 
one's opinion really matters. But that took time, so I have grown as a person that way (First Nations, Female Youth).

Another participant highlighted how participating in sport and physical activity increased her epistemology:

...doing traditional canoeing, I was talked to by my dad a lot and, like our Elder said, he said a couple of the things we need to do is pray and that was a big thing for travel journeys, is praying and respecting the cedar, respecting the canoe, respecting the paddle, the environment that you're in, the tribes, the nations that you were going to visit - that was a huge thing ...(First Nations, Female Youth).

An example quote for wellness:

...being able to develop in a healthy environment, being able to develop healthy choices when it comes to eating, when it comes to learning about healthy habits, whether it's in sports or eating or in education and so that you can, I think it is important to have, to be surrounded by education, healthy eating, sport, so that you can develop as an individual (Inuit, Female Youth).

However, the cultural topic of repression was discussed by some participants:

Growing up identifying as a First Nations student, I found it really rough just because of the stereotype of how you are supposed to look. I am fair-skinned, you know, people don't think that I have 'Native Eyes', and they go 'you're not Native' and I get it from both my community and outside of my community (First Nations, Female Youth).

\section{Connection}

Connecting with peers, friends, community, coaches, the land, and the Creator were important themes reported by youth. The following quote exemplifies the role of sport in building connections with peers and community:

... the team dynamic really helped me grow more connected to my community spiritually. Having a close-knit team dynamic and wanting to support each other in the sport and then wanting to represent your community so you feel a respect for the community and wanting to, bring something back to it (Inuit, Female Youth). 
Another Inuit female youth participant provided an example quote of connections with community and friends:

I've played soccer since I was really young and it's been a big part of my life and helped me form kind of, bonds with a lot of my friends, like, they say the same thing. And so that has been really important for me and making those connections and finding those connections as important and I continue to have that, keep that. That's still important for me today, finding those connections and support with other people and creating that community, you know? (Inuit, Female Youth).

Similarly, a participant highlighted the role of sport in promoting connections with community:

When you think about sports down south, schools compete against each other in tournaments. Here we don't have that size. We have to compete against other towns. So, a tournament is a competition of schools down south whereas here it brings the whole town, like, the whole town is involved. It definitely brings the community together (Inuit, Female Youth).

An example of sport fostering connections with friends, peers and coaches is demonstrated in this participant quote:

I've been involved in sport for so long that I don't know what my life would be like without it. (laughs) I've made so many good friends. It definitely helped me to, build my own confidence in myself...I had a really close team all throughout high school and they are very supportive. I had a very supportive coach and it was just very good for me emotionally in that way. I always had people to help me out when I needed it (Inuit, Female Youth).

In the sharing circle, participants also discussed connections with the land, this First Nation male youth quote is an example:

Myself, I still, I'm not an active person when it comes to actually organized sports but I still get out with, hiking, things like that, like I'm always on the lake, I'm always, in the Gatineau Park, I know it inside and out. The parks back home, it is stuff like that, for me, it's more connected towards the bush that I notice I excel... (First Nation, Male Youth).

Finally, Indigenous youth talked of connections with the creator, an example quote is: 
I do jigging and I really enjoy it...it makes me comfortable, makes me just want to dance. And, I enjoy doing it with others as well. So, it is spiritual in a sense but, with the creator, but also spiritual with the people that I am doing it with, I feel connected with them in that type of way (Métis, Female Youth).

\section{Supports}

Participants identified the influential role of supports in their participation and development including the role of family, coaches, peers/friends, role models, respected advisors, and community members. The supportive role of the coach was identified:

...when there is someone there to guide you and show you what you should be doing. You don't really know and you tend to question yourself a lot more and you're not really sure that what you're doing is right. So it makes it less likely that you are going to stick with the sport and so it is really important to have a strong coach who has good leadership skills and that you can look up to... (First Nations, Female Youth).

Peers and friends were also identified as key supports for the youth:

A lot of my friends that I hung out with from kindergarten until I went to high school, they dropped out of school, they have been in and out of the court system, they've committed suicide...because of sport and because of the positive influence my friends have had on me, I think I've been able to take a different avenue in life (Inuit, Female Youth).

The importance of a role model was described by a Métis female youth:

So, in the development of youth I think a big part of it is influence from peers and older people. Having a good, a big influence on the youth development and with focus on the future and with what they want to be and how you can help them accomplish that (Métis, Female Youth).

Finally, the role of a respected advisor was highlighted:

Still have all of my teachings so the process of learning that it helped me a lot. It made me feel accepted. It made me understand a lot more about my culture. And it opened a lot of doors. I got to meet a lot of cool people and Elders that also fed me with more teachings (First Nations, Female Youth). 


\section{Self}

Enhanced self-awareness was identified by the participants as a benefit of involvement in sport and physical activity. An example of enhanced self-awareness, "Cause it [sports and physical activity] makes you feel better, it makes you feel healthy and, when I feel healthy, I feel a lot better about myself"' (Indigenous Female Youth). Indigenous youth also discussed enhanced life purpose from their involvement in sport and physical activity:

I was finally on a volleyball team...so with that, it came with much responsibility because you had to wake up much earlier because of the practices and stuff like that. So, it made me feel like I had more of a purpose. So, I guess the more stuff, the more activities you do, the more you feel like you have accomplished things in your life (First Nations, Male Youth).

\section{Physical Activity Outcomes}

Indigenous youth reported positive outcomes through engagement in physical activity including physical, cognitive, and emotional benefits as well as personal development. A cognitive example was shared by an Indigenous youth:

I find that physical activity helps me focus and, in school, if I have a paper that I have to write then I am like 'ah, I don't know what I am going to do, I can't get my thoughts around it.' Then I go and do the opposite for a bit, and it will help me get my mind off of things and come back and refocus and be able to do whatever I needed to do (Métis, Female Youth).

Another youth drew links between enhanced physical and mental health from physical activity:

I think another thing, just because of anxiety, I was lacking sleep, so, because I do physical activity, and the yoga also helped me sleep, so, once you get sleep you start, your brain gets all those chemicals working in there and it starts to settle. So, it also helped with sleep, so, in turn it helped with my anxiety (First Nations, Female Youth).

Indigenous youth discussed the opportunities provided through engagement in sport:

It's a first time a lot of people leave home... sometimes it's an experience of a lifetime even to just come to Iqaluit or to go to Ottawa or to Yellowknife for Super Soccer. It's a first time that some people get to do things and experience a 
city or a bigger place outside of their community and I think that's important (Inuit, Female Youth).

In addition to positive outcomes, negative outcomes were reported. An example of a negative outcome was offered by a Métis, female youth:

I actually got a lot of concussions in sports, which didn't really help with my focus with school work but, I just found sports that had, less physical contact, and that seemed to help better like swimming. So, I think if you find the right sport and don't get hurt then it works out well (Métis, Female Youth).

\section{Education}

Indigenous youth discussed education and its role with sport and physical activity involvement positively, negatively and in relation to future goals. As an example of future education goals, "A goal is to continue my education. I did pretty good last year...so, my goal is to continue with that" (First Nations, Male Youth). Another youth reflected on the important role of school:
Ah, well, I'm trying to finish off my school, or I am going to school right now and down the road I am going to start a business pretty soon here and then. And I just thank the Creator for keeping me alive and waking up next day and, that's why I am going to school to develop my brain, my education and I am going to go about to make this business and then two years down the road I will be a millionaire and I won't have to care (laughter). You know, I don't beat around the bush I just get straight to business. So, but, ah, I guess, you know, I just want to develop myself into a good person, I guess, that's why I try to do all of these programs (Indigenous, Male Youth).

\section{Negative Life Experiences}

Indigenous youth discussed the role of physical activity with a number of negative life experiences. Indigenous youth also described the issues with the justice system, family and in the community such as the high incidence of suicide, racism, drug and alcohol abuse, gangs, and negative use of time notably, time spent being sedentary while gaming. The youth did discuss the potential positive role of sport to overcome these challenges as supported by this quote. "That (sport) is important because, too many kids here that drink a lot, do drugs a lot, get into trouble and it would be good to try and develop the youth around here" (First Nations, Male Youth). 


\section{Barriers}

Indigenous youth discussed barriers to physical activity including the intrapersonal barriers of lack of time:

I am so focused on all the negative that is going on in my life and worrying about facing that instead of actually trying to enjoy my time while I am going through all of that. So, I guess I just kind of think that "oh, I have to go through all of this crap" so I don't have time for that (First Nations, Female Youth).

A second barrier that was identified was lack of access. For example, an Elder described the difficulty for some youth to attend cultural events and ceremonies out of the city:

.... a lot of things are going against you. For example finances; in order to get involved in something, be it physical activity or sports or cultural stuff, powwows, you need to get to these places, ceremonies. Sometimes they are out of Toronto, they are way out and it is difficult to get there. If you don't have the people to support you or you don't have the finances, it makes it extra hard... (Indigenous Elder).

\section{Physical Activity and Recreation}

The final theme was physical activity and recreation. Within the theme, participants discussed sport, extracurricular involvement and physical activity generally. As an example, a female participant discussed her traditional dancing:

I played basketball a lot at the park with the guys in my neighbourhood...But, um, something that has always been consistent with me with physical activity is powwow dancing. I am a jingle dress dancer too and, now I am learning the hoop dance and it's a lot of work (First Nations, Female Youth).

As another example, a First Nation female youth described how she has been impacted by her experiences:

When I think back to my participation in sport, recreation and physical activity, I think, I have grown a lot...It has impacted me in a positive way, emotionally, mentally and spiritually...I do dancing as well. Jingle dress dancing that has impacted me in a big way (First Nation, Female Youth). 
As a last example, a quote was provided describing the importance of extracurricular involvement:

I think it's also important just to be involved in extracurricular activities so you can make friends and get support, and feel like you belong and are in some kind of community. And also the skills you get from that. I never was in a lot of extracurricular activities when I was younger, and I think in a lot of ways that held me back (First Nation, Female Youth).

\section{Discussion}

The purpose of this research was to understand Indigenous youth development through sport and physical activity through the voices, stories, and experiences of Indigenous youth using a Two-Eyed Seeing approach. As Garrett and colleagues (2014) suggested, it is important to understand the "lives and worldviews of Native youth....to hear and understand their voices, their stories, and their experiences" (p. 471). Ten main themes were identified during the qualitative analytical process. Consistent with a recent review of the literature (Bruner et al., 2016), both positive (e.g., personal development, enhanced connections with community) and negative experiences (e.g., injuries, racism) were reported by youth.

Indigenous youth discussed how involvement in sport and physical activity influence each of the four quadrants of the Medicine Circle including cognitive (e.g., increased confidence, concentration), physical (e.g., more energy, better sleep), emotional (e.g., more happiness, enjoyment, satisfaction), and spiritual (e.g., wellbeing, identity) dimensions. Youth also discussed the importance of wholistic balance and attention to each of the four quadrants. Youth experiencing balance reported spending time with family, and participating in community, cultural and sporting activities. There is an integration and complementarity of activities.

A common theme among Indigenous youth was the reporting of connections to others through engagement in sport and physical activity. Specifically, Indigenous youth reported enhanced connections to family, community, friends, peers, culture, land, and their ancestors. While other researchers (e.g. Hawkins \& La Marr, 2012) have demonstrated the ways in which youth become connected to culture through physical activity and sport, Kiran and Knights (2010) found that Traditional Indigenous Games (TIG) did not contribute to cultural connectedness among Indigenous and Torres-Strait Islander youth. Despite their traditional design, these findings may be partially explained by the contemporary use of equipment that meant the TIG may not have been reflective of Aboriginal or Torres-Strait Island culture. It may be that physical activity and sport programming needs to be community-driven and land-based to 
support cultural resurgence, and wholistic balance, for Indigenous youth (Big-Canoe \& Richmond, 2014).

The important role of development through sport and physical activity participation was also described by Indigenous youth in relation to enhanced awareness of oneself and the attributes arising from engaging in sport and physical activity. Similarly, a study with Native American youth in the southwestern United States described the role a running group had on connecting youth with their identity and contributing to the "collective memory" of the region (Rodriguez, 2012). Additionally, sport and physical activity was perceived to help youth overcome negative life experiences in their social environment such as the suicide of friends and family members, witnessing drug and alcohol abuse and involvement in gangs. Youth that took part in a study conducted by Baillie and colleagues (2016) also identified the importance of physical activity and sport in helping youth deal with hardships, including pressures to use illicit substances and alcohol. More specifically, Indigenous youth who took part in an equine program noted the role physical activity can play in healing for those who have misused illicit substances and alcohol in the past (Adams et al., 2015).

Indigenous youth described the role of sport participation in relation to culture. Specifically, youth described the influence of sport on well-being by keeping youth away from drugs and alcohol, making healthy choices and developing healthy habits (e.g., healthy eating). Further, sport was identified as playing a vital role in the development of an Indigenous youth's identity in relation to learning a sense of pride in themself, being strong, and comfortable with oneself, and discovering one's capabilities. Despite the reported benefits of sport on culture in the study and in the literature (e.g., Tighe \& McKay, 2012) in relation to the other three quadrants, there was less frequent reporting of the spiritual impact of sport and physical activity. The meaning of spirituality can vary greatly from person to person (RCAP, 1996). This may make it difficult to formulate specific questions that target the role of sport and physical activity on spirit and culture. Furthermore, Indigenous youth may choose to discuss their experiences of sport and physical activity based on the physical nature of the activity (Isaak \& Marchessault, 2008) or simply not use the term "spirituality" in their daily conversation (Hanson \& Randazzo, 2011). Thus, our findings may also be attributed to adolescent Indigenous youth focusing on the other three quadrants without seeing the connection between sport and physical activity and spirit. Further research is merited.

In addition to the positive experiences, Indigenous youth reported a number of negative experiences, including injuries related to physical activity and sport participation. According to Byrnes and colleagues (2015), physical activity and sport are the leading cause of injury for youth in Canada. While injuries may be considered as unintended negative consequences of physical activity and sport, some sharing circle participants opted for low impact activities that reduced their risk of injury. For Indigenous youth, low contact sports may be an alternative that is supportive of participation across 
ages, genders, and abilities (Ruhanen \& Whitford, 2011). More inclusive physical activity and sport opportunities may be especially important in rural and remote communities where programming sustainability is dependent upon increasing the number of youth involved (Baillie et al., 2016).

Indigenous youth also shared experiences involving lateral violence and racism when participating in physical activity and sport. According to Lawrence (2004), Indigenous peoples with a degree of European ancestry may sometimes be denied their Indigeneity and forced to struggle with an "in-between identity". For some of the sharing circle participants, this violence manifested based on skin colour as well as particular Indigenous identities (e.g. identifying as a Métis person). The presence of lateral violence can, at least in part, be attributed to the attempted erasure of Indigenous ancestry by the Canadian nation-state, especially during the Residential School era and the Sixties Scoop (Alfred \& Corntassel, 2005; Lawrence, 2004). Other youth described racism that tainted their physical activity and sport experiences. Several authors (e.g., Blodgett et al., 2008; Churchill et al., 1979; Coram, 2007) have noted the role that physical activity and sport has played in characterizing Indigenous athletes as purely animalistic physical beings. Despite the central role of erasure of Indigenous identity in the Canadian colonial context, participant narratives also demonstrated resiliency and pride in their identity in the face of ongoing colonisation.

Several Indigenous youth described barriers, both at the intrapersonal and community level, which influenced their experiences of physical activity and sport. For many youth, time devoted to other tasks such as study, work, and family translate into less time for physical activity and sport participation. Mason and Koehli (2012) noted that many Indigenous youth devote significant amounts of time to their family. One possible way to enhance physical activity and sport experiences for Indigenous youth with family responsibilities may be to provide opportunities for physical activity that includes the family unit (Kerpan \& Humbert, 2015). Indigenous youth also recognized that limited access to physical activity and sport opportunities acted as a barrier. For some Indigenous youth, place of residence was a significant barrier, whether opportunities were limited because of the rural or remote location of the community (Baillie et al., 2016; Byrnes et al., 2015) or the socioeconomic status of the urban neighbourhood they resided in (Kerpan \& Humbert, 2015). Even when opportunities were physically accessible, access to transportation and the cost of the activity were commonly mentioned communitylevel barriers. Previous research has also identified transportation as a significant structural barrier to physical activity and sport across rural and remote as well as urban contexts (Mason \& Koehli, 2012).

Through sharing their stories, it was evident that Indigenous youth received varying types of support from a wide range of sources to help them overcome barriers to participate in sport and physical activity. Sources of support included family, community, respected advisors, peers/friends, role models, and coaches. Similarly, other studies have identified peers and family (Schinke et al., 2010), coaches (Blodgett et al., 2008), and the community (McHugh, 2011; McHugh, Coppola, Holt \& Anderson, 2015) 
as common sources of support for physical activity and sport. Notably, youth did not mention the role that ancestors and animals play in supporting physical activity and sport particular (Adams et al., 2015; Baillie et al., 2016). Types of support included examples of four dimensions of social support as outlined by Wills and Shinar (2000) including emotional support (confidence, security, feeling loved and cared for), esteem support (support for competence, self-esteem), informational support (receiving advice, guidance), and instrumental or tangible support (practical assistance and resources such as rides, financial support and equipment). Not surprisingly, scholars have reported the significant role that social support plays in physical activity and sport experiences for Indigenous youth (Kerpan \& Humbert, 2015), demonstrating that social support may act as a protective factor for Indigenous youth facing interpersonal and structural barriers.

There are some notable limitations with the present research. While participants were drawn from a variety of populations (urban, rural, and remote), Indigenous identities (First Nations, Métis, and Inuit), genders, and ages with unique experiences of physical activity and sport, all sharing circles were analysed together. Each Nation/community and its members will have unique relationships with the land, the Canadian state, and colonisation, all of which influence physical activity and sport (Blodgett et al., 2008). Although attempts have been made to capture the experiences of Indigenous youth with diverse identities, these themes are not necessarily reflective of the experiences of all Indigenous youth across Canada. Furthermore, the Indigenous team members who led the analysis were viewing the data through their own cultured lens. Thus, the analysis and transferability of the findings is limited to specific Indigenous identities in Canada.

Secondly, given that the identity of individual youth could not be ascertained in the sharing circle transcripts, member checking could not be conducted and the confirmability of the data was limited in this sense (Shenton, 2004). Further, youth participants did not take part in the analysis of sharing circle data. With the growing popularity of community-engaged research approaches among Indigenous peoples in Canada (Petrucka, Bassendowski, Bickford, \& Goodfeather, 2012), youth are increasingly being asked to interpret their own data in a process that can facilitate the sharing of Indigenous voices, by Indigenous youth (Castleden, Garvin \& Huu-ay-aht First Nation, 2008). We recognise the importance of creating spaces for Indigenous youth to take part in research, it is noteworthy that our research team consisted of both Indigenous and non-Indigenous researchers, involved Indigenous youth researchers in the coding process, and sought feedback from an Indigenous governing council including Indigenous youth guiding the project.

\section{Future Directions}

To our knowledge, this study is among the first to examine the experiences of Indigenous youth in sport and physical activity using a Two-Eyed Seeing (Bartlett, Marshall, Marshall, 2012) analytical 
approach. As a framework, two-eyed seeing can help allied researchers and Indigenous co-researchers move towards new ways of producing knowledge that prioritizes co-learning. Specifically, co-learning can provide opportunities where both Indigenous knowledges and Western knowledge systems can be brought together to recognize the ways in which domination of Western knowledge has limited scientific inquiry. An overarching goal for both community members and allied researchers should be to produce research about physical activity and sport that is more considerate of multiple perspectives (Martin, 2012). Guided by Two-Eyed Seeing, future research should go beyond Etuaptmunk to emphasize and centre Indigenous ways of knowing. When knowledge centres Indigenous ways of knowing, knowledge can become more meaningful, action-oriented, and beneficial for Indigenous youth and their communities (Kovach, 2009; Muhammad et al., 2015). As an example, it may be fruitful to integrate the findings and knowledge offered by the youth into a novel measure evaluating Indigenous youth development in sport and physical activity. Such research would build upon a recent review highlighting a need for more culturally relevant, validated measures of Indigenous youth development in sport and physical activity (Bruner et al., 2016). Through greater integration and understanding of Indigenous knowledges, sport and physical activity programs and interventions can be created, evaluated, and ultimately improved to help Indigenous youth achieve wholistic balance from the experience and in their lives.

\section{Conclusion}

Utilizing a Two-Eyed Seeing approach, we aimed to investigate and share stories about Indigenous youth development within sport and physical activity. This journey involved a collective colearning process bridging Indigenous knowledges with a Western method. Findings from the study contribute to the growing empirical evidence of Indigenous youth development through sport and physical activity and highlight important avenues of future research. 


\section{References}

Adams, C., Arratoon, C., Boucher, J., Cartier, G., Chalmers, D., Dell, C. A., et al. (2015). The helping horse: How equine assisted learning contributes to the wellbeing of First Nations youth in treatment for volatile substance misuse. Human-Animal Interaction Bulletin, 1(1), 52-75.

Alfred, T., \& Corntassel, J. (2005). Being Indigenous: Resurgences against contemporary colonialism. Government and Opposition, 40(4), $597-614$.

Allen, J. B. (2003). Social motivation in youth sport. Journal of Sport \& Exercise Psychology, 25, 551567. doi:10.1123/jsep.25.4.551

Baillie, C. P., Galaviz, K. I., Emiry, K., Bruner, M. W., Bruner, B. G., \& Lévesque, L. (2016). Physical activity interventions to promote positive youth development among Indigenous youth: a RE-AIM review. Translational Behavioral Medicine, 1 - 9. doi: 10.1007/s13142-016-0428-2

Bartlett, C., Marshall, M., \& Marshall, A. (2007). Integrative science: Enabling concepts within a journey guided by trees holding hands and two-eyed seeing, Two-eyed Seeing Knowledge Sharing Series, Manuscript No. 1, Institute for Integrative Science \& Health (www.integrativescience.ca), Cape Breton University at Sydney, Nova Scotia, Canada

Bartlett, C., Marshall, M., \& Marshall, A. (2012). Two-eyed seeing and other lessons learned within a co-learning journey of bringing together Indigenous and mainstream knowledges and ways of knowing. Journal of Environmental Studies and Sciences, 2(4), $331-340$.

Bartlett, C., Marshall, M., Marshall, A., \& Iwama, M. (2015). Integrative science and two-eyed seeing: Enriching the discussion framework for healthy communities. In Ecosystems, society, and health: Pathways through diversity, convergence, and integration. McGill-Queen's University Press.

Big-Canoe, K., \& Richmond, C. A. (2014). Anishinabe youth perceptions about community health: Toward environmental repossession. Health \& Place, 26, $127-135$.

Blodgett, A. T., Schinke, R. J., Fisher, L. A., Wassengeso George, C., Peltier, D., Ritchie, S., et al. (2008). From practice to praxis: Community-based strategies for Aboriginal youth sport. Journal of Sport and Social Issues, 32(4), $393-414$.

Blodgett, A. T., Schinke, R. J., Fisher, L. A., Yungblut, H. E., Recollet-Saikkonen, D., Peltier, D., et al. (2010). Praxis and community-level sport programming strategies in a Canadian Aboriginal reserve. International Journal of Sport and Exercise Psychology, 8(3), 262 - 283. doi: 10.1080/1612197X.2010.9671953 
Bronfenbrenner, U. (1977). Toward an experimental ecology of human development. American Psychologist, 32(7), 513. doi: 10.1037/0003-066X.32.7.513

Bronfenbrenner, U. (1979). The ecology of human development: Experiments by nature and design. Cambridge, MA: Harvard University Press.

Bruner, M. W., Hillier, S., Baillie, C. P., Lavallée, L. F., Bruner, B. G., Hare, K., \& Lévesque, L. (2016). Positive youth development in Aboriginal physical activity and sport: A systematic review. Adolescent Research Review, 1(3), 257 - 269. doi: 10.1007/s40894-015-0021-9

Byrnes, J., King, N., Hawe, P., Peters, P., Pickett, W., \& Davison, C. (2015). Patterns of youth injury: a comparison across the northern territories and other parts of Canada. International Journal of Circumpolar Health, 74(1), 27864.

Canadian Heritage. (2005). Towards a new beginning: A foundation report for a strategy to revitalize First Nation, Inuit and Métis languages and cultures: Report to the minister of Canadian heritage by the task force on Aboriginal languages and cultures (Rep.). Ottawa, Ontario: Task Force on Aboriginal Languages and Cultures. Retrieved from http://publications.gc.ca/collections/collection_2018/pch/CH4-96-2005-eng.pdf

Castleden H., Garvin T. \& Huu-Ay-Aht First Nation. (2008). Modifying photovoice for communitybased participatory Indigenous research. Social Science and Medicine, 66(6), 1393-1405.

Churchill, W. (1979). An historical overview of twentieth century Native American athletics. Indian Historian, 12(4), $22-33$.

Coram, S. (2007). Race formations (evolutionary hegemony) and the aping' of the Australian Indigenous athlete. International Review for the Sociology of Sport, 42(4), 391 - 409.

Côté, J., \& Fraser-Thomas, J. (2011). Youth involvement and positive development in sport. In P.R.E. Crocker (Ed.). Sport psychology: A Canadian Perspective (2nd ed., pp.226-255). Toronto: Pearson Prentice Hall.

Eccles, J. S., Barber, B. L., Stone, M., \& Hunt, J. (2003). Extracurricular activities and adolescent development. Journal of Social Issues, 59, 865 - 889. doi:10.1046/j.0022- 4537.2003.00095.x

Estes, C. P. (1992). Women who run with the wolves: Myths and stories of the wild woman archetype. New York: Ballantine Books. 
First Nations Information Governance Centre (FNIGC). (2012). First Nations Regional Health Survey (RHS) 2008-10. National report on adults, youth and children living in First Nations communities. Ottawa: FNIGC

Forsyth, J., \& Giles, A. R. (Eds.). (2013). Aboriginal Peoples and Sport in Canada: Historical Foundations and Contemporary Issues. Vancouver, British Columbia, Canada: UBC Press.

Fredericks, J. A., \& Eccles, J. S. (2006). Is extracurricular participation associated with beneficial outcomes? Concurrent and longitudinal relations. Developmental Psychology, 42(4), 698. doi:10.1037/0012-1649.42.4.698

Fredericks, J. A., \& Eccles, J. S. (2008). Participation in extracurricular activities in the middle school years: Are there developmental benefits for African American and European American youth? Journal of Youth and Adolescence, 37, 1029-1043. doi:10.1007/s10964008-9309-4

Garrett, M. T., Parrish, M., Williams, C., Grayshield, L., Portman, T. A. A., Rivera, E. T., et al. (2014). Invited commentary: Fostering resilience among Native American youth through therapeutic intervention. Journal of Youth and Adolescence, 43(3), 470 - 490.

Hanna, R. (2009). Promoting, developing, and sustaining sports, recreation, and physical activity in British Columbia for Aboriginal youth. Document created for First Nations Health Society [online]. Retrieved from http://www.fnhc.ca/pdf/

Sports_Recreation_and_Physical_Activity_BC_Aboriginal_Youth.pdf

Hanson, K. H., \& Randazzo, S. (2011). Survival then, survival now. International Journal of Sport \& Society, 2(4), 83-96.

Hawkins, E. H., \& La Marr, C. J. (2012). Pulling for native communities: Alan Marlatt and the journeys of the circle. Addiction Research \& Theory, 20(3), 236 - 242.

Hillier, S.A. (2019). First Nations Health Policy and Funding: Consequences for those Living with HIV/AIDS. Ryerson University Library: Digital Repository.

Hovey, R. B., Delormier, T., McComber, A. M., Lévesque, L., \& Martin, D. (2017). Enhancing Indigenous health promotion research through two-eyed seeing: A hermeneutic relational process. Qualitative Health Research, 27(9), 1278 - 1287. doi:10.1177/1049732317697948

Isaak, C. A., \& Marchessault, G. (2008). Meaning of health: The perspectives of Aboriginal adults and youth in a northern Manitoba First Nations community. Canadian Journal of Diabetes, 32(2), 114 -122 . 
Kerpan, S., \& Humbert, L. (2015). Playing together: The physical activity beliefs and behaviors of urban Aboriginal youth. Journal of Physical Activity and Health, 12(10), 1409 - 1413.

Kiran, A., \& Knights, J. (2010). Traditional Indigenous games promoting physical activity and cultural connectedness in primary schools -- Cluster randomised control trial. Health Promotion Journal of Australia, 21(2), 149 - 151.

Kovach, M. (2009). Indigenous methodologies: Characteristics, conversations and contexts. Toronto, Ontario, Canada: University of Toronto Press.

Lavallée, L. (2007). Physical activity and healing through the medicine wheel. Pimatisiwin: A Journal of Aboriginal and Indigenous Community Health, 5(1), 127 - 153.

Lavallée, L. (2008). Balancing the medicine wheel through physical activity. Journal of Aboriginal Health, 1(4).

Lavallée, L. F. (2009). Practical application of an Indigenous research framework and two qualitative Indigenous research methods: Sharing circles and Anishnaabe symbol-based reflection. International Journal of Qualitative Methods, 8(1), 21 - 40.

Lavallée, L., \& Lévesque, L. (2013). Two-eyed seeing: Physical activity, sport, and recreation promotion in Indigenous communities. In J. Forsyth \& R. Giles (Eds.), Aboriginal peoples \& sport in Canada: Historical foundations and contemporary issues (pp. 206 - 228). Vancouver, British Columbia, Canada: UBC Press.

Lawrence, B. (2004). "Real" Indians and others: Mixed-blood urban Native peoples and Indigenous nationhood. Lincoln, NE: University of Nebraska Press.

Lerner, R. M., Lerner, J. V., Almerigi, J. B., Theokas, C., Phelps, E., Gestdottir, S., et al. (2005). Positive youth development, participation in community youth development programs, and community contributions of fifth grade adolescents: Findings from the first wave of the 4-H study of positive youth development. Journal of Early Adolescence, 25, 17 - 71.

doi:10.1177/0272431604272461

Lockard, V. (2000). Native American sports council gets honor. From Canku Ota: A newsletter celebrating Native America. Retrieved May 08, 2017, from http://www.turtletrack.org/Issues00/Co02122000/CO_02122000_sportscouncil.html

Lovelace, R. (2009). Notes from Prison: Protecting Algonquin Lands from Uranium Mining. Speaking for Ourselves: Environmental Justice in Canada. 
Martin, D. H. (2012). Two-eyed seeing: A framework for understanding Indigenous and non-Indigenous approaches to Indigenous health research. Canadian Journal of Nursing Research, 44(2), 20 - 42.

Mason, C., \& Koehli, J. (2012). Barriers to physical activity for Aboriginal youth: Implications for community health, policy, and culture. Pimatisiwin: A Journal of Aboriginal and Indigenous Community Health, 10(1), $97-107$.

McHugh, T. L. F. (2011). Physical activity experiences of Aboriginal youth. Native Studies Review, 20(1).

McHugh, T. F., Coppola, A. M., \& Sinclair, S. (2013). An exploration of the meanings of sport to urban Aboriginal youth: A photovoice approach. Qualitative Research in Sport, Exercise and Health, 5(3), 291 - 311. doi:10.1080/2159676X.2013.819375.

McHugh, T. L. F., Coppola, A. M., Holt, N. L., \& Andersen, C. (2015). “Sport is community:” An exploration of urban Aboriginal peoples' meanings of community within the context of sport. Psychology of Sport and Exercise, 18, $75-84$

McHugh, T. L. F., Deal, C. J., Blye, C. J., Dimler, A. J., Halpenny, E. A., Sivak, A., et al. (2018). A meta-study of qualitative research examining sport and recreation experiences of Indigenous Youth. Qualitative Health Research, 1049732318759668.

McNiff, S. (1998). Art-based research. London: Jessica Kingsley Publisher.

McNiff, S. (1998). Trust the process: An artist's guide to letting go. Boston: Shambhala Publications

Muhammad, M., Wallerstein, N., Sussman, A. L., Avila, M., Belone, L., \& Duran, B. (2015). Reflections on researcher identity and power: The impact of positionality on community based participatory research (CBPR) processes and outcomes. Critical Sociology, 41(7-8), 1045-1063.

National Aboriginal Health Organization. (2005). First Nations regional longitudinal health survey (RHS) 2002/03: The peoples' report. Ottawa: Author.

Peltier, C. (2018). An application of two-eyed seeing: Indigenous research methods with participatory action research. International Journal of Qualitative Methods, 17, 1-12.

Petrucka, P., Bassendowski, S., Bickford, D., \& Goodfeather, E. V. (2012). Towards building consensus: Revisiting key principles of CBPR within the First Nations/Aboriginal context. Open Journal of Nursing, 2(02), 143 
Rodriguez, R. (2012). Corriendo educando or teaching/learning while running. International Journal of Critical Indigenous Studies, 5(1), 79-92. https://doi.org/10.5204/ijcis.v5i1.96

Royal Commission on Aboriginal Peoples. Final Report, Volume 4-Perspectives and realities. The search for belonging: Perspectives of Aboriginal youth. 1996.

Ruhanen, L., \& Whitford, M. (2011). Indigenous sporting events: More than just a game. International Journal of Event Management Research, 6(1), $33-51$.

Schinke, R., Yungblut, H., Blodgett, A., Eys, M., Peltier, D., Ritchie, S., et al. (2010). The role of families in youth sport programming in a Canadian Aboriginal reserve. Journal of Physical Activity and Health, 7(2), 156 - 166. doi: 10.1123/jpah.7.2.156

Shenton, A. K. (2004). Strategies for ensuring trustworthiness in qualitative research projects. Education for information, 22(2), 63-75.

Stokols, D. (1992). Establishing and maintaining healthy environments: Toward a social ecology of health promotion. American Psychologist, 47(1), 6 - 22. doi: 10.1037/0003-066X.47.1.6

Tighe, J., \& McKay, K. (2012). Alive and kicking goals!: Preliminary findings from a Kimberley suicide prevention program. Advances in Mental Health, 10(3), 240 - 245.

Wills, T. A., \& Shinar, O. (2000). Measuring perceived and received social support. In S. Cohen, L. G. Underwood, \& B. H. Gottlieb (Eds.), Social support measurement and intervention: A guide for health and social scientists (pp. 86-135). Oxford Press.

http://dx.doi.org/10.1093/med:psych/9780195126709.003.0004 